\title{
Effective Motivational Tools in Hotel Industry
}

\author{
Neeraj Kumari ${ }^{1}$ \\ 'Associate Professor (Management) Faculty of Engineering \& Technology, Manav Rachna International \\ Institute of Research and Studies (Deemed to be University), NAAC Accredited 'A' Grade University Faridabad, \\ India. \\ Email: neerajnarwat@gmail.com Tel: +91-9711889788
}

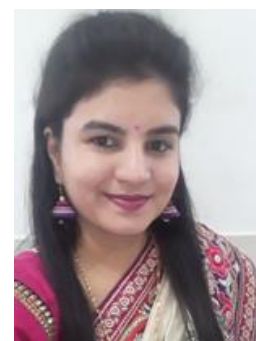

\begin{abstract}
Motivation is especially important in the hospitality and tourism industry, where competence and employee satisfaction are key determinants of service quality. The study aims to find out the important factors which motivate the working personnel in the hospitality industry. The primary data has been collected through a structured questionnaire. The questionnaires were filled by 5 Managers and 40 employees of the Oberoi Hotel, New Delhi. Simple random sampling has been used. For the hotel industry in particular, training is a useful tool for an effective development of the human resource. The job in a hotel involves lot of work pressures and the employees need to be able to cope with this. Though the purpose of training in Hotel is to prepare the employees for future assignments but still training empowers him with knowledge and skill, which in turn affects his motivation level. Thus Training although traditional, still retains its position as an important motivational tool.
\end{abstract}

Keywords: Training, Performance, Rewards.

JEL Classification: M53; M19; M50.

Citation | Neeraj Kumari (2018). "Effective Motivational Tools in Hotel Industry". Asian Journal of Social Sciences and Management Studies, 5(3): 91-101.

History:

Received: 5 December 2017

Revised: 25 May 2018

Accepted: 28 May 2018

Published: 31 May 2018

Licensed: This work is licensed under a Creative Commons

Attribution 3.0 License (cc) E E

Publisher: Asian Online Journal Publishing Group
Funding: This study received no specific financial support.

Competing Interests: The author declares that there are no conflicts of interests regarding the publication of this paper.

Transparency: The author confirms that the manuscript is an honest, accurate, and transparent account of the study was reported; that no vital features of the study have been omitted; and that any discrepancies from the study as planned have been explained.

Ethical: This study follows all ethical practices during writing.

\section{Contents}

1. Introduction

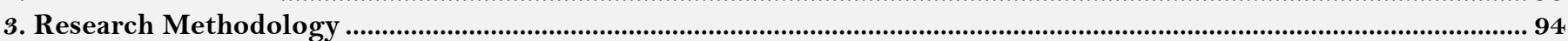

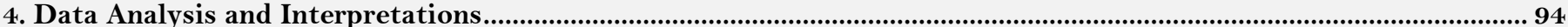

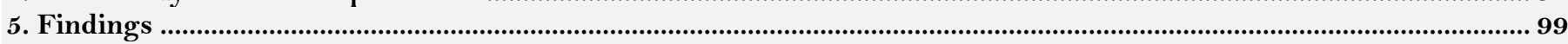

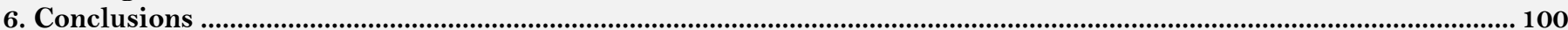

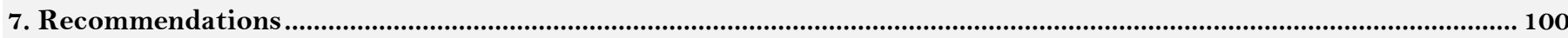

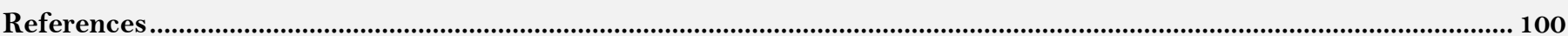




\section{Introduction}

\subsection{Motivation}

Since increase in productivity is the ultimate goal of every industrial organization, motivation of employees at all levels is the most critical function of management. An organization has goals, which can only be achieved by the efforts of the people who work in the organization. Individuals have their own goal in life, and these are likely to be different from those of the organization. A major consideration for supervisors and management is the problem of getting the employees to work in such a way that the organization achieves its goals.

Motivation is concerned with why people choose a particular course of action in preference to others, and why they continue with a chosen action, often over a long period, and in the face of difficulties and problems. If a manager wants to improve the work of the organization, attention must be given to the level of motivation of its members. The manager must also encourage staff to direct their efforts (their driving force) towards the successful attainment of the goals and objectives of the organization.

Motivation is a complex subject, it is a very personal thing, and it is influenced by many variables. Individuals have a variety of changing, and often conflicting, needs and expectations which they attempt to satisfy in a number of different ways.

\subsection{Motivational Tools}

A manager needs to get to know his or her employees. By being really worried about every representative, the administrator will realize what inspires every person. A few specialists react to private compliments on their work, while others blossom with formal acknowledgment. Still others - especially sales representatives - work hardest when a liberal commission program is advertised. Furthermore, some need to take a shot at unique activities.

\subsection{Six Big Motivators}

- Exciting work and test

- Career development

- Learning and improvement

- Working with extraordinary individuals

- Fair pay

- Supportive administration/great manager.

Administrators who comprehend what inspires every representative can tailor motivators likewise. Some tools to motivate employees are given below:

\subsection{Reward Management}

Rewards are critical to training because they reinforce the effort employees are putting forth. Reward early and often, Immediacy is important. Frequency also matters; reinforcing behavioral changes is most effectively done via rewarding participants at frequent intervals.

Personalization is very important. The mix that you select can motivate anyone and everyone. This is especially true when it comes to enterprise-wide programs intended to teach and motivate employees across demographic lines. Even a rewards program for lower-level, part-time or hourly employees should include aspirational items, since the act of setting goals is motivational.

\subsection{Financial Rewards Criteria}

The criteria for assessing the effectiveness of financial reward practices as means of motivation are that:

- They are, beyond what many would consider possible, inside impartial and also remotely aggressive (in spite of the fact that there will dependably be a pressure between these two criteria - paying business sector rates may disturb inner relativities);

- Pay-for-performance systems are made in the light of an understanding that immediate inspiration just happens if the prizes are beneficial, if they are specifically related to fair, objective and appropriate performance measures, if employees understand what they have to achieve, and if their expectations on the likelihood of receiving the reward are high;

- Employees understand how the financial reward system operates, how they benefit from it, and how the organization will help them to develop the skills and competences they need to receive the maximum benefit.

\subsection{Non-Financial Rewards}

Non-financial rewards can be centered around the necessities a great many people have, despite the fact that to various degrees, for accomplishment, acknowledgment, obligation, impact and self-improvement.

- Achievement: The requirement for accomplishment is characterized as the requirement for aggressive achievement estimated against an individual standard of greatness. Achievement motivation can be increased by organizations through processes such as job design, performance management, and skill or competencyrelated pay schemes.

- Recognition: Recognition is one of the most impactful motivators. Individuals need to know not just how well they have accomplished their destinations or did their work yet in addition that their accomplishments are valued. Acclaim, nonetheless, ought to be given sensibly - it must be identified with genuine accomplishments. Furthermore, it isn't the main type of acknowledgment. Financial rewards, particularly accomplishment rewards granted instantly after the occasion, are unmistakably images of acknowledgment to which are connected substantial advantages, and this is an essential manner by which commonly strengthening procedures of financial and non-financial rewards can work. There are different types of acknowledgment, for example, long administration grants, materialistic trifles of some kind, vacations and business related treks 
abroad, which can all be a piece of the aggregate reward process.

- Responsibility: Employees can be motivated by being given more responsibility for their own work. This is basically what strengthening is about and is in accordance with the idea of characteristic inspiration in view of the substance of the activity. It is also related to the fundamental concept that individuals are motivated when they are provided with the means to achieve their goals.

- Influence: Individuals can be inspired by the drive to apply impact or to practice control. The organization, through its policies for involvement, can provide motivation by putting people into situations where their views can be expressed, listened to and acted upon. This is another aspect of empowerment.

- Personal growth: Yearning and decided individuals will look for and discover these open doors for themselves, in spite of the fact that the association needs to clear up the extension for development and advancement it can give (if it does not, they will go away and grow elsewhere).

Increasingly, however, individuals at all levels of organizations, whether or not they are eaten up by ambition, recognize the importance of continually upgrading their skills and of progressively developing their careers. This is the rationality of ceaseless improvement. Numerous individuals now see access to preparing as a key component in the general reward bundle. The accessibility of learning openings, the choice of people for high-notoriety instructional classes and programs and the accentuation set by the association on the securing of new aptitudes and also the improvement of existing ones, would all be able to go about as effective inspirations.

\section{Literature Review}

Rao and Rao (2017) it concludes that employee engagement is a two-way street. The instruments and methods received by pioneers can be connected in any industry and in any size of an association. The social ramifications of the exploration recommend that pioneers can guarantee representative commitment by following these inventive devices and methods. It beseeches the two bosses and representatives to take responsibility for parts and duties to accomplish hierarchical brilliance and viability.

Hussein (2017) there was a positive connection between's the season of administration and extraneous rewards just like a dependable purpose behind better accomplishment of authoritative execution as given by a $21.7 \%$ relationship which was huge. The discoveries proposed that there was an essentialness connection between motivational devices, for example, compensation; compensation, suggestion, acknowledgment and so forth get by specialists and their execution. More research ought to be led on the relationship and impact of prizes on specialist's execution utilizing numerous private and open associations.

Nandhini (2017) the inherent components contribute more in the activity fulfillment of the representatives than the outward factors. This leads to employee's motivation on organizational effectiveness which results in the employee's job satisfaction.

Downes et al. (2017) Findings indicated that autonomous motives were positively related to goal-specific efficacy and perceived Person-Organization (PO) fit (Time 1), and showed indirect effects on goal accomplishment and other-rated job satisfaction (Time 2). Controlled thought processes were adversely identified with similar middle people and results. Objective thought processes embroil objective particular results, and people's general composition of objective intentions - over their objectives - shape their objective adequacy and PO fit observations. These systems identify with distal results of objective achievement and occupation fulfillment. The exploration offers hypothetical ramifications for the proximal results of objective intentions, yet additionally handy ramifications for manners by which associations can enhance occupant PO fit recognitions.

Serrat (2017) learning is the key to success. Some would even say survival in today's organizations. Information ought to be persistently advanced through both inward and outer learning. For this to happen, it is important to help and empower association, individuals, information, and innovation for learning.

Kumari (2016) out of the two chose associations, variety among the workers of Taj Mahal inn is less when contrasted with other association of the investigation. Indisputably it might be expressed that Worker Fulfillment is a multidimensional wonder with various components working at the same time. There are certain factors which have strong influence on the overall index but the presence of other factors cannot be ignored.

Pramanik and Chatterjee (2015) the findings revealed that significant and positive relation existed between intrinsic motivation, emotional intelligence, and organizational citizenship behavior. Characteristic inspiration and enthusiastic insight together anticipated $27 \%$ of the aggregate fluctuation of authoritative citizenship conduct. Characteristic inspiration and authoritative citizenship conduct were observed to be better if there should be an occurrence of private-area workers than in the event of open division representatives. As it was discovered that inborn inspiration and enthusiastic insight are decidedly identified with authoritative citizenship conduct, so businesses may propel their representatives inherently to hold them and keeping in mind that contracting, bosses may consider applicants with high passionate knowledge that can profit the association.

Chauhan (2015) when associations focus on non-financial devices, for example, chance of expanding occasion and family benefits, the representative may see the association as a supporting and minding association. Prizes are imperative factors that clarify certain activity perspectives that contribute altogether to the association, for example, work fulfillment. The significant target of the examination is looking at the significance of non-fiscal impetuses in an association. The examination inferred that keeping in mind the end goal to bring "great work inspiration" and not just "cash inspiration" distinctive kinds of non-financial motivations must be presented in an association. Non-money related acknowledgment can be extremely propelling, building sentiments of certainty and fulfillment.

Kumari (2015) the addition in the level of passionate insight of workers brings about a greater amount of common help, regard and gaining from each other. Among eight clashes determination styles, bargain (approach) and dispersion (evasion) styles are altogether anticipated by passionate knowledge. Dispersion is observed to be best anticipated by passionate insight. The representatives in the examination had better than expected level of enthusiastic knowledge and are decidedly and essentially identified with their execution in the association. More elevated amount of passionate insight drives representatives towards arrangement with association's objectives and goals. 
Alam (2015) it is discovered that the vast majority of the Medical Promotion Officers (MPOs) are not happy with their employments and for this they are not roused and for this their turnover propensity is high. The MPOs are disappointed with their employer stability, societal position, working burden, visit to retailers' shop, deals focus on, no space for family, not getting the retirement advantage and not getting the family protection bolster. It is recommended by the power field examination demonstrate for expelling the limiting/negative powers factors for decreasing the turnover rate.

Kumari (2015) preparing is a urgent procedure in an association and accordingly should be all around outlined. In particular, the preparation projects ought to give satisfactory learning to all representatives, guarantee adjust strategies are utilized for the choice of students, and keep away from any view of biasness. The study concluded that the employees were not fully satisfied by the separation of the training program into two parts, on the job and off the job training, but if sufficient data would have been provided to the employees in advance, this could have helped them during the training process.

Kumari (2014) the study concluded that there exists a relationship between perceived fairness of performance appraisal and employee performance. The aftereffect of the measurable investigation was that there exists a huge effect of apparent reasonableness of execution evaluation on worker execution. The examination presumes that apparent reasonableness of execution evaluation conduct assumes an extremely essential part in adding to authoritative working and execution accordingly giving a superior lucidity to the connection between representative execution and saw decency of execution evaluation.

Aarabi et al. (2013) the outcomes demonstrated that among the motivational components, two factors were observed to be huge indicators of employment execution. Preparing contributed $40.4 \%$ to work execution while advancement contributed an extra $3 \%$. Inherent motivational variables are viewed as more essential contrasted with outward motivational factors, for example, installment, professional stability, and neighborly condition. Opportunity a natural variable however was not observed to be essentially identified with work execution.

Kilam and Kumari (2012) career growth and development needs a consciously planned effort on the part of the individual careerist and the same cannot be left to chance. Nearly $81 \%$ respondents perceived that well-established Private Sector in India and the foreign banks had better Career Planning \& HRD System as compared to that in Indian Public Sector Banks. Over the years and in tune with the changing times, Indian Public Sector Banks have reviewed their HR \& promotion policy and now for bright, hardworking and knowledgeable employees it takes comparatively lesser time to move to higher levels in banking hierarchy. This attitudinal change has to be ongoing \& purposive.

Kumari (2011) the investigation estimated the level of worker fulfillment at Goodbye Steel. Preparing was the factor which added to worker fulfillment more than different variables. Alternate measurements crosswise over which the representative fulfillment was estimated were Prevalent Subordinate relationship, Part, Culture, Profession Advancement, Objectives and Inspiration.

\section{Research Methodology}

The lodging business is anticipated to develop significantly in the years ahead. There is an incredible requirement for professionally prepared work force at both operational and administrative levels. An essential administrative capacity in any association is to rouse workers. This is on account of inspiration is inseparably connected to worker fulfillment and guarantees representatives reliably exceed expectations at their occupations. Inspiration is particularly imperative in the cordiality and tourism industry, where representative fulfillment and capability are key determinants of administration quality. The research aims to the following objectives:

- To find out the factors which motivate hospitality industry employees

- To find out whether Hospitality Industry employees get motivated through Training or not

\subsection{Data Collection Methods}

a) Secondary data: The main sources of secondary data were the internet, books and journals on motivation and training and reward management and FHRAI magazine.

b) Primary Data: The primary data has been collected through a structured questionnaire. The questionnaire had both open ended and closed-ended questions. I have contacted some of the Managers and their employees of the Oberoi Hotel to get their views on the research topic.

Sample size: The questionnaires were filled by 5 Managers and 40 employees of the Oberoi Hotel, New Delhi.

Sampling Technique: Simple random sampling has been used in the study.

\section{Data Analysis and Interpretations}

\subsection{Analysis for Managers}

1. Do you agree to the statement "Motivation comes from within an individual? No amount of HR practices can influence motivation levels of employees". 


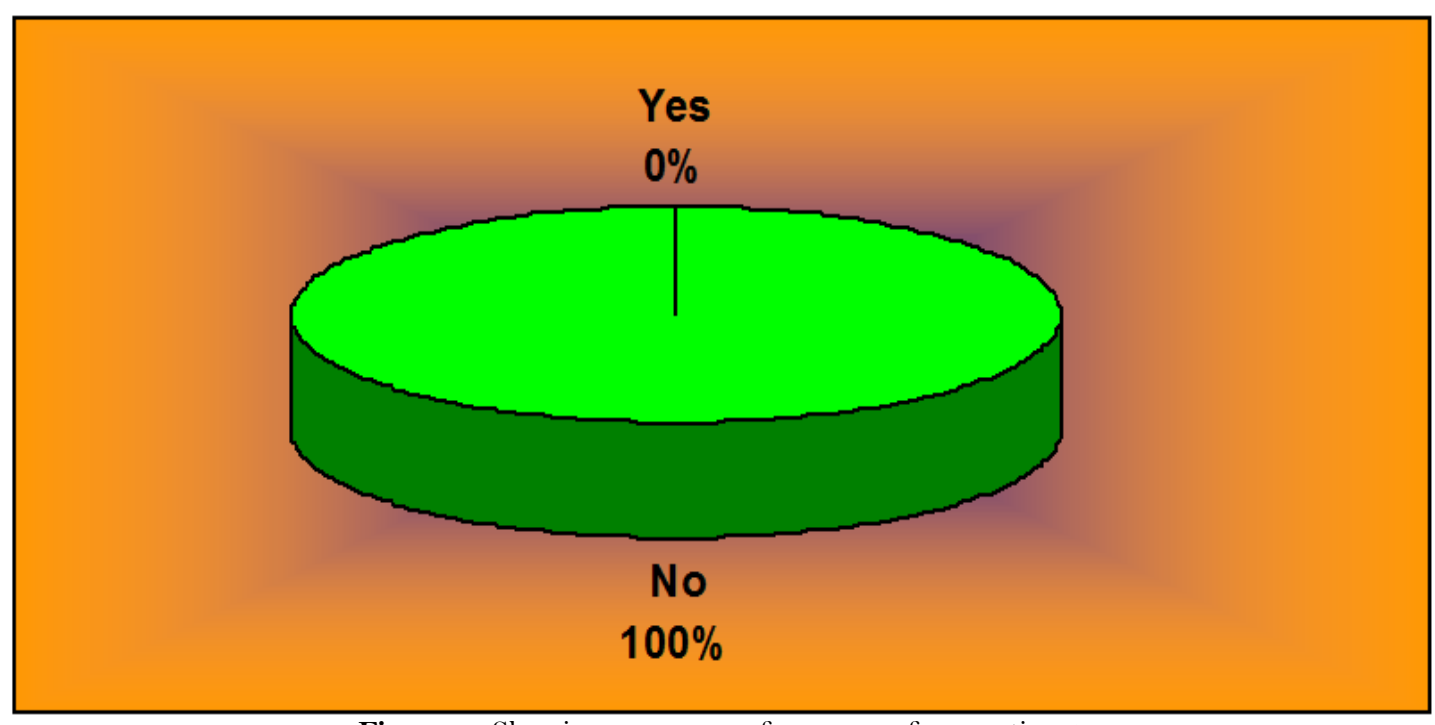

Source: Self made from the responses of the questionnaire

Interpretation: Above graph shows that most of the respondents do not agree to the fact that motivation comes from within an individual. HR practices can influence motivation levels of the employees.

2. Do you think that motivation and productivity of Hospitality employees are interrelated?

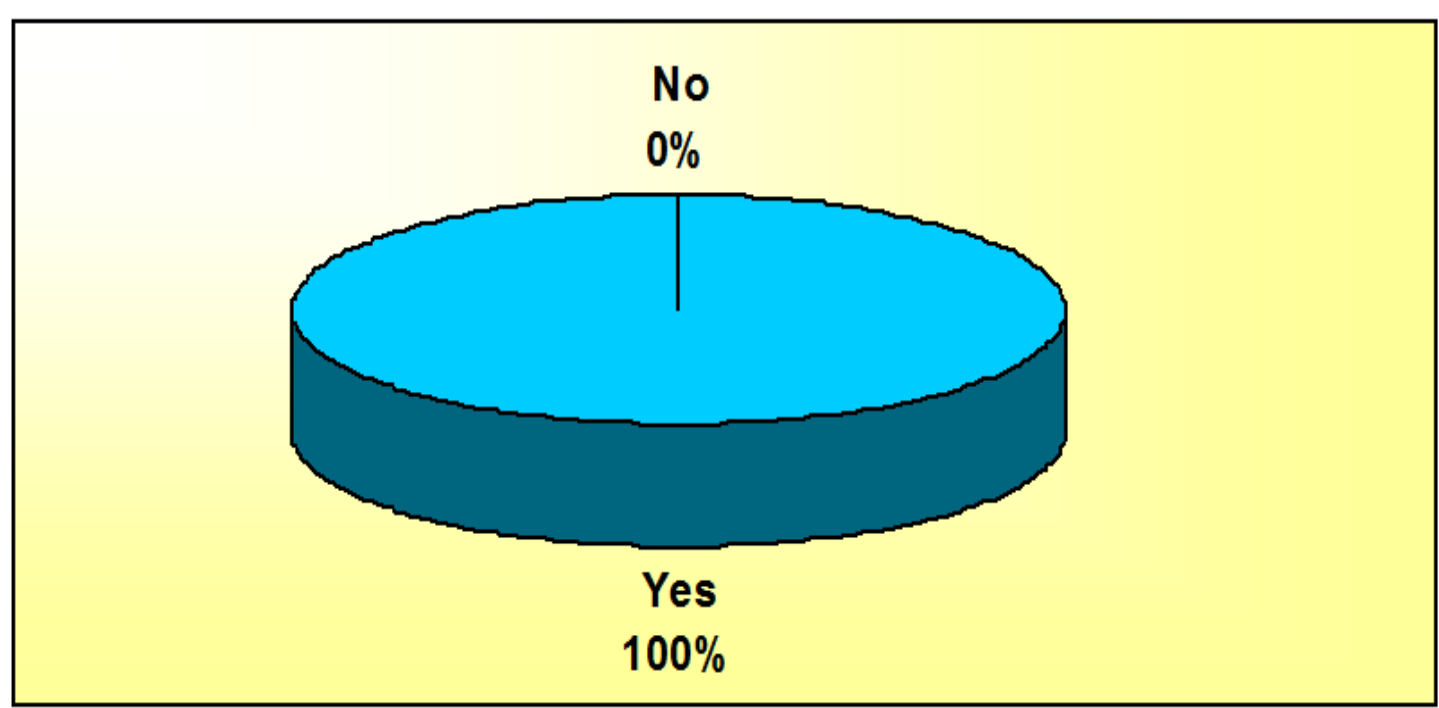

Figure-2. Showing responses of managers for question 2

Source: Self made from the responses of the questionnaire

Interpretation: According to the survey all the Managers agree to the fact that motivation and productivity of Hospitality employees are interrelated.

3. What are the factors that motivate employees in your organization? Please rank the motivation factors as to how they motivate you to perform well (on a scale of 1 to 6 ) for the following (6- Highly Motivating, 1- least Motivating):

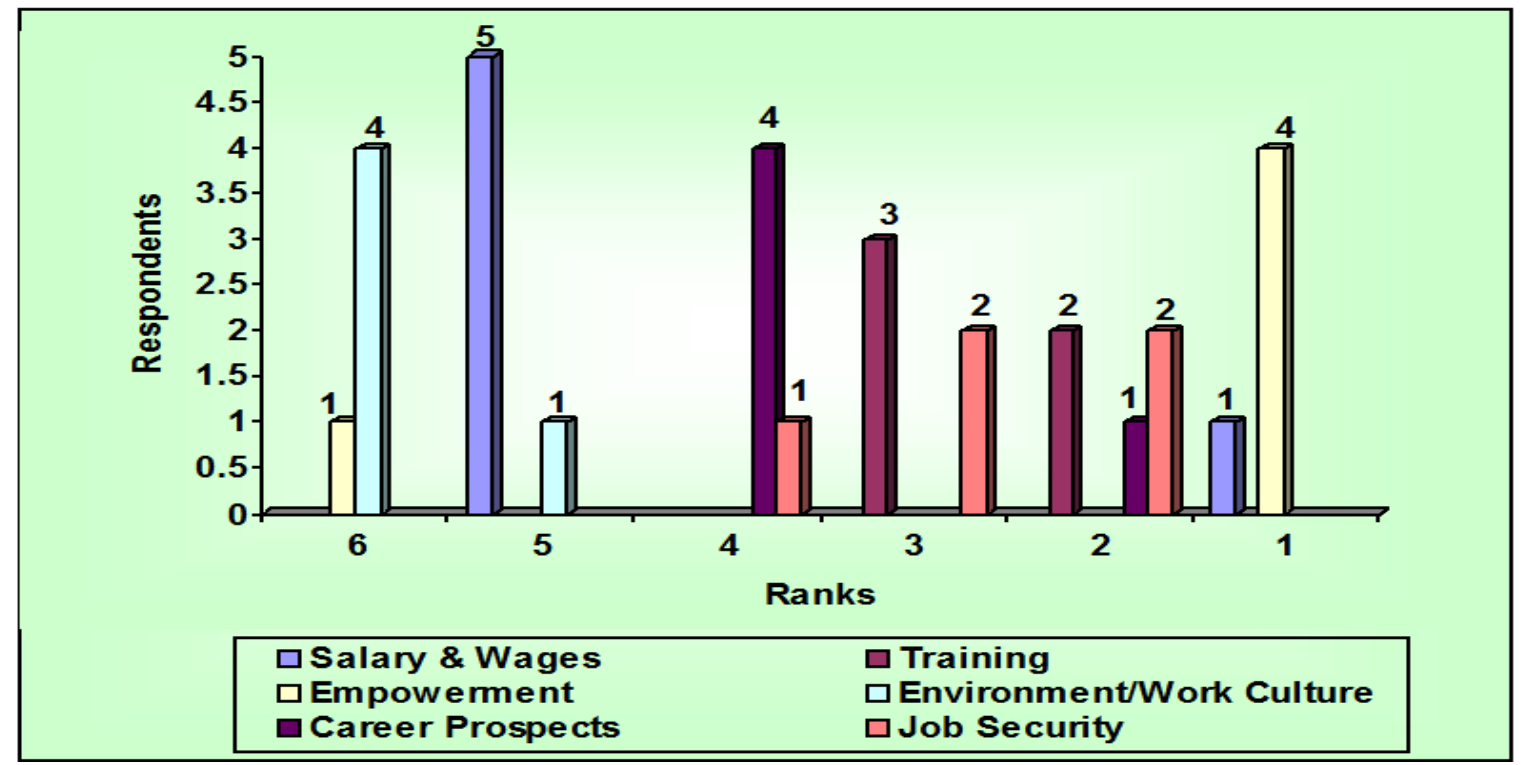

Source: Self made from the responses of the questionnaire

Interpretation: Salary and wages have been ranked as motivating factor by four Managers while only one Manager has ranked it as least motivating. Training has been ranked 3 by three Managers and 2 by two Managers that indicates that training is not an important motivating factor. One Manager has ranked empowerment as 
highly motivating while only four Managers have ranked it as least motivating. All the Managers have ranked environment and work culture as a motivating factor. Job security has been ranked 3 by two Managers, 2 by two Managers and 4 by 1 Managers. It indicates that job security is not an important motivating factor.

4. Do you think that training is an important tool to enhance the performance of employees?

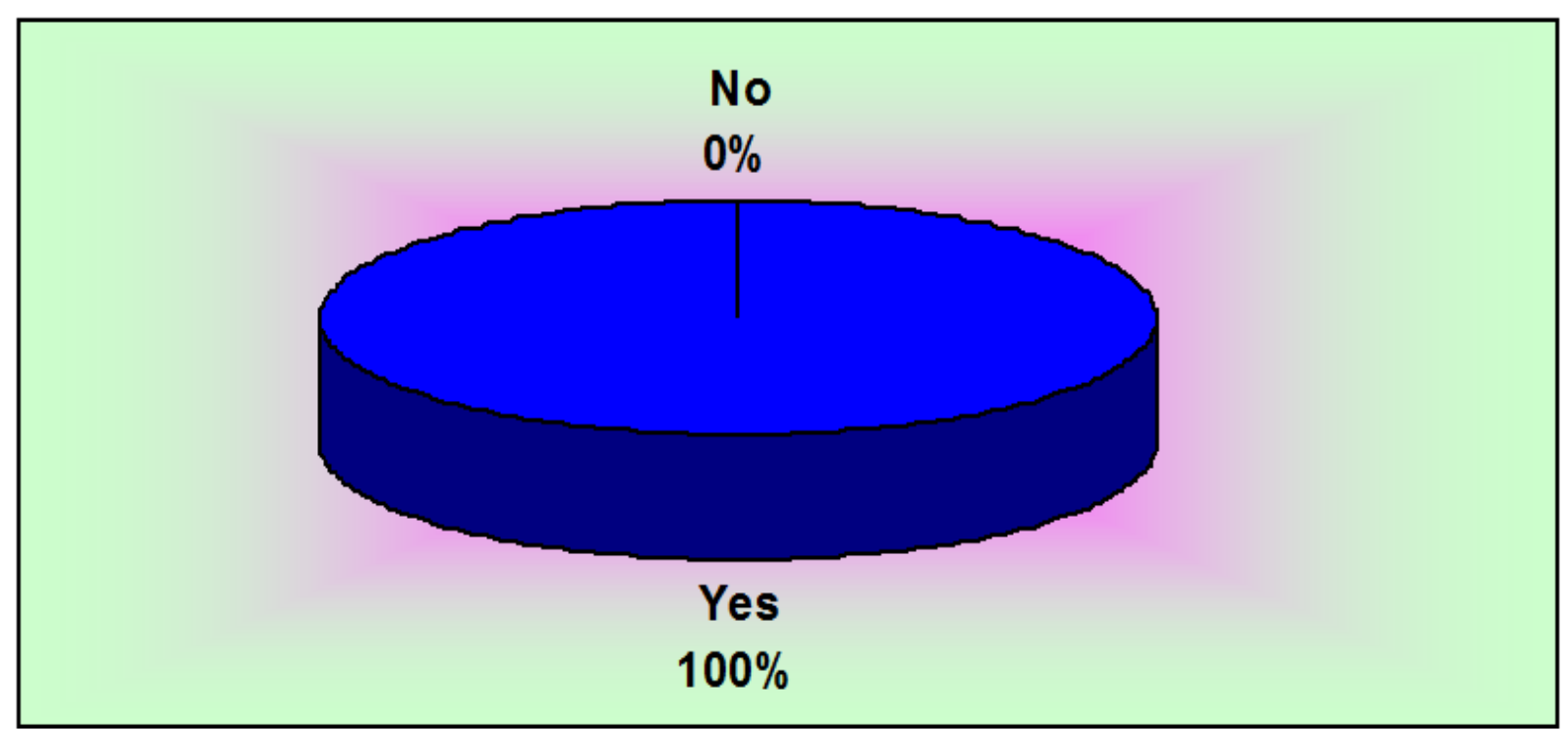

Figure-4. Showing responses of managers for question 4

Source: Self made from the responses of the questionnaire

Interpretation: All the managers agree to the fact that training is an important tool to enhance the performance of the employees.

5. What according to you is the purpose of training in the Hospitality Industry?

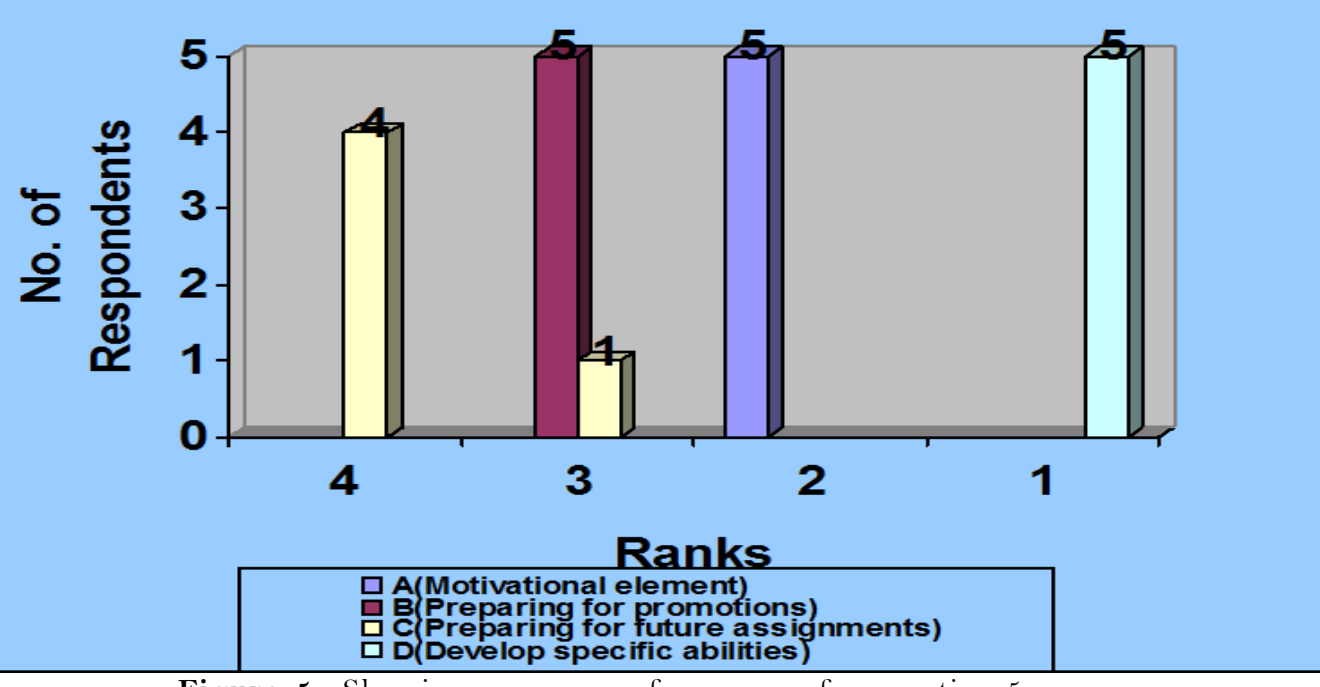

Figure-5. Showing responses of managers for question 5

Source: Self made from the responses of the questionnaire

Interpretation: The most important purpose of training as per the Managers is preparing for future assignments in the same position. The next important purpose is preparing for promotions. All the Managers have ranked training as a second motivational element. While development of specific abilities and competence have been ranked as 1 .

6. What kind of training programs do you have in your organization?

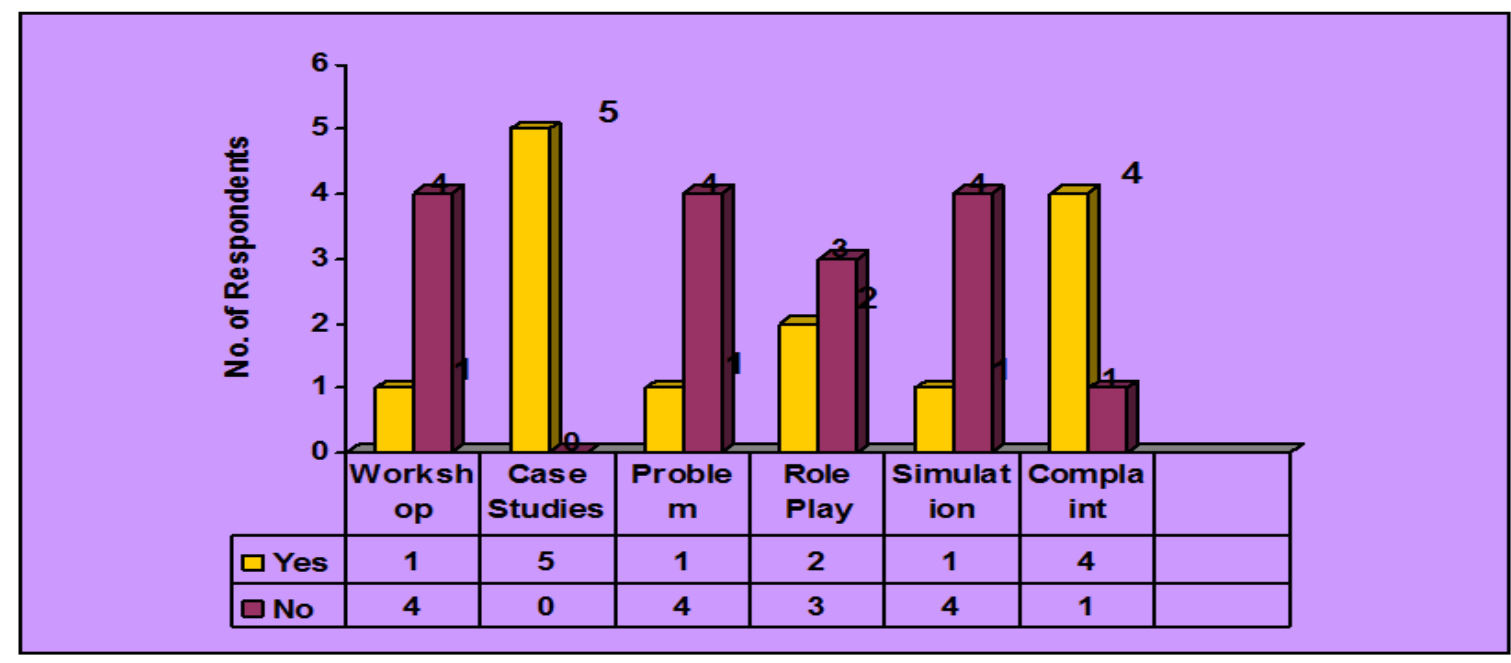

Figure-6. Showing responses of managers for question 6

Source: Self made from the responses of the questionnaire 
Interpretation: Above graph shows that the hotel imparted case study training to the employees followed by complaint handling training.

7. Do you evaluate your training programs for effectiveness of training?

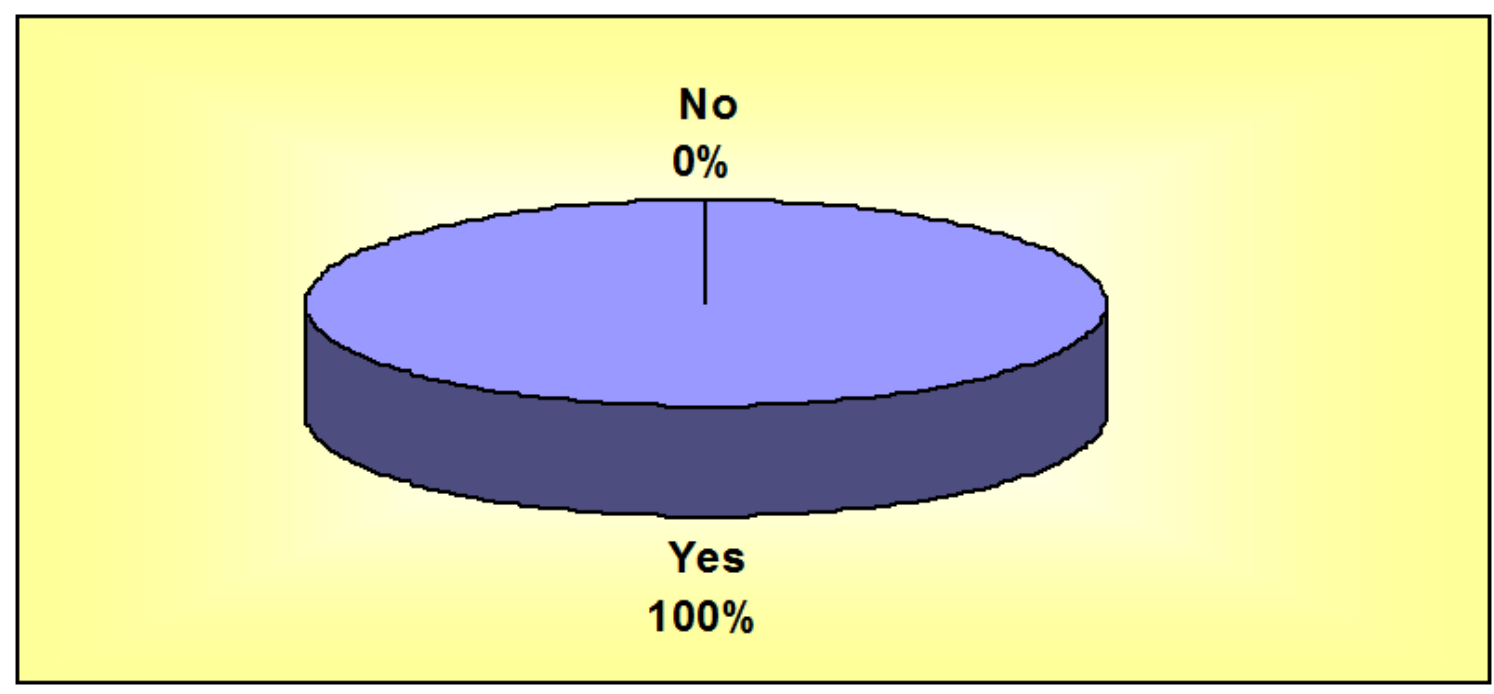

Figure-7. Showing responses of managers for question 7

Source: Self made from the responses of the questionnaire

Interpretation: The hotel evaluates their training programmes for the effectiveness of the training.

8. Please rate the training programmes conducted in your organization on a scale of 1-4? (1- least, 4- most)

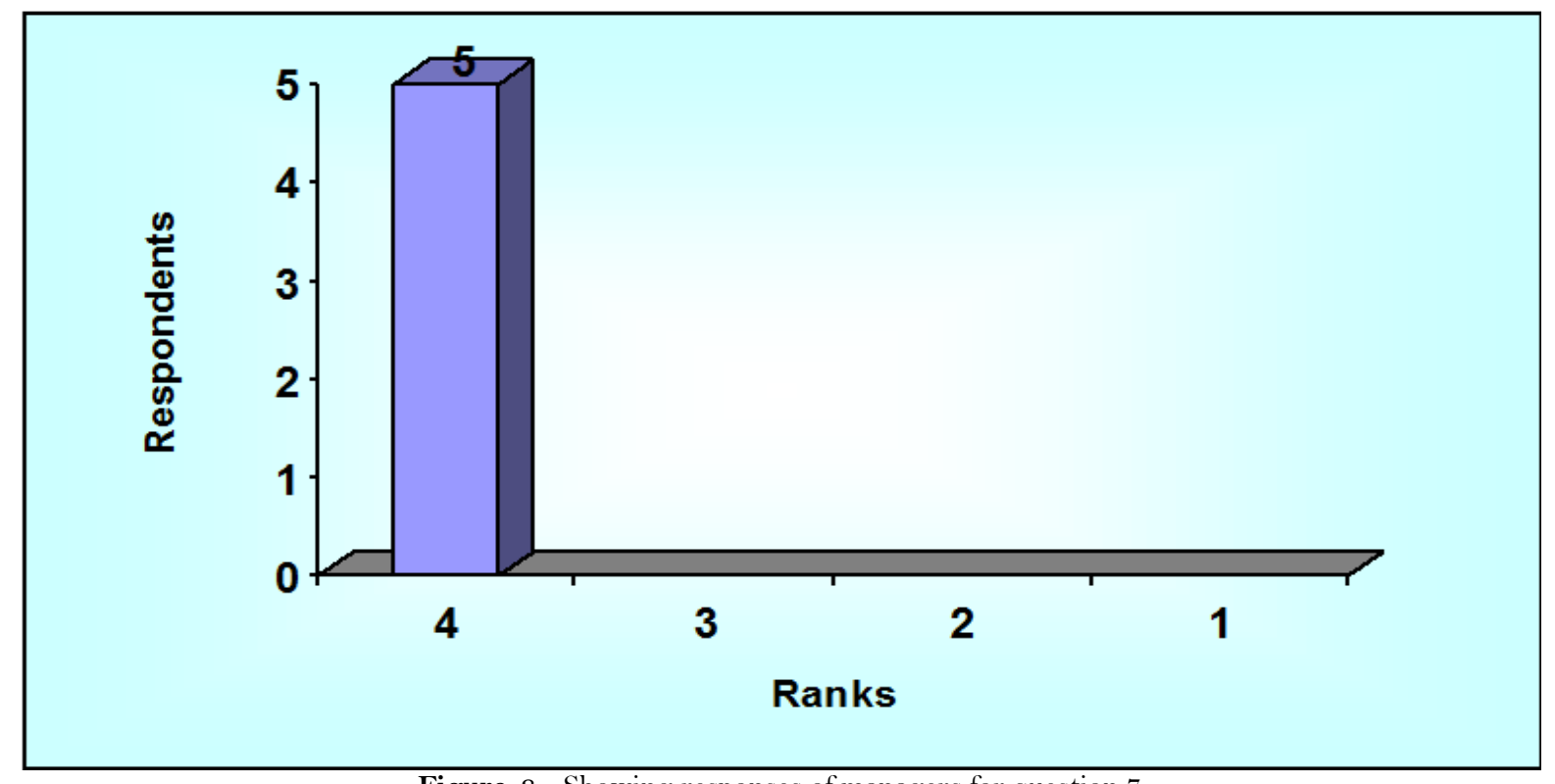

Figure-8. Showing responses of managers for question 7

Source: Self made from the responses of the questionnaire

Interpretation: Above bar graph shows that all the Managers are satisfied with the training conducted in their organisation.

\subsection{Analysis for Employees}

1. Do you agree with the statement that motivation leads to improved productivity?

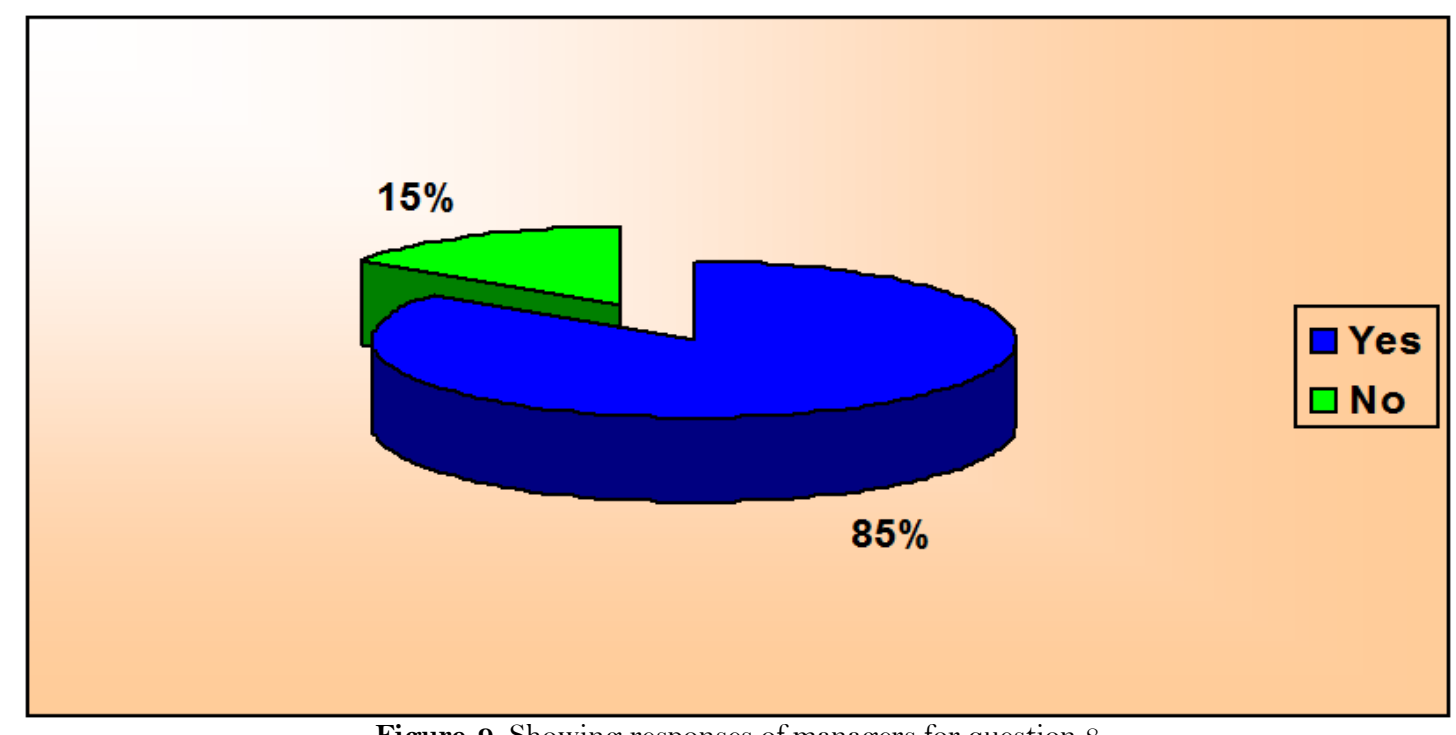

Figure-9. Showing responses of managers for question 8

Source: Self made from the responses of the questionnaire 
Interpretation: From the survey of the employees, $85 \%$ of the employees agree with the statement that motivation leads to improved productivity and $15 \%$ of them do not agree to this statement.

2. What are the various tools used by your organization to motivate the employees?

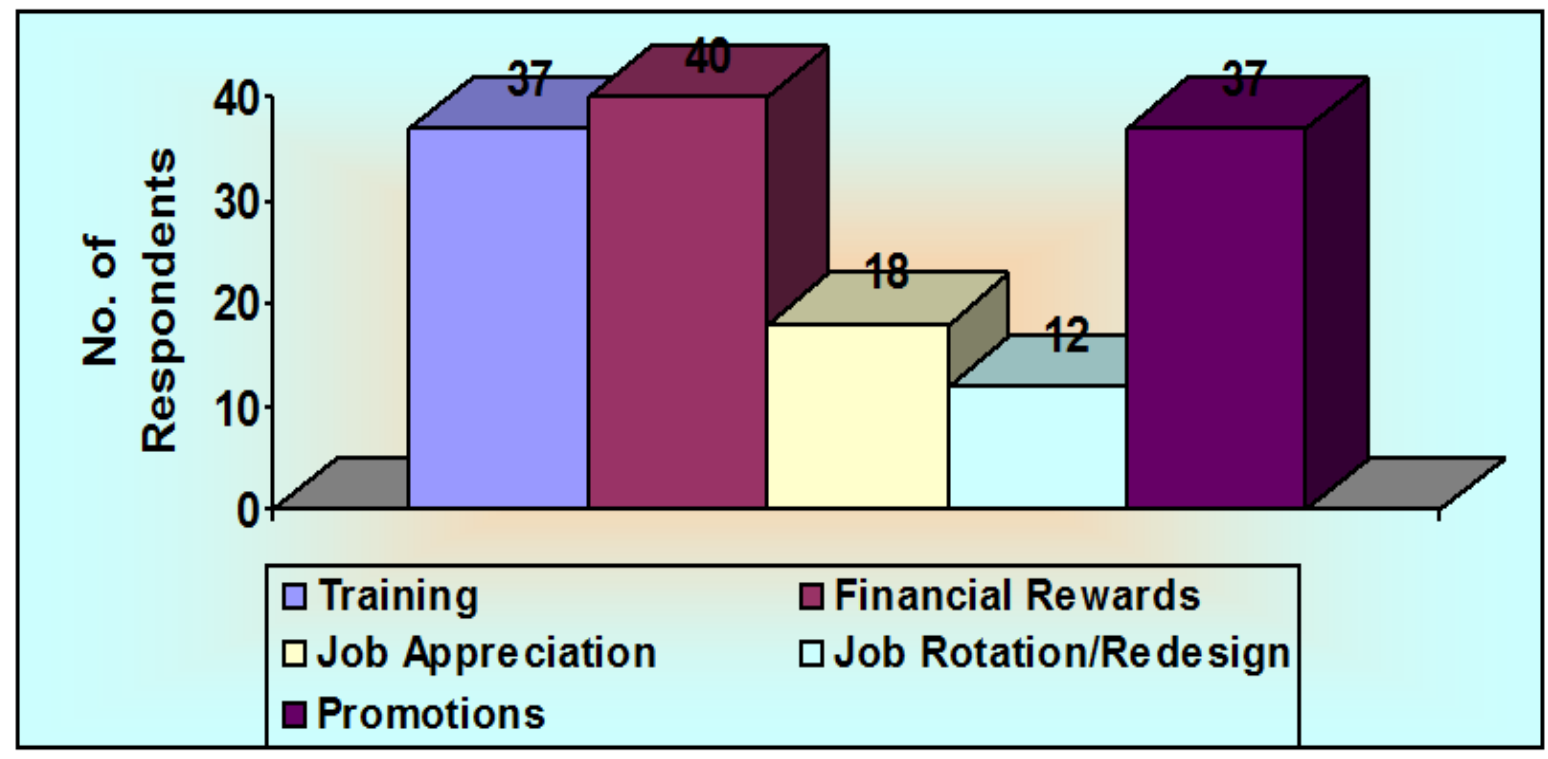

Source: Self made from the responses of the questionnaire

Interpretation: Financial rewards are used by organizations to motivate employees. Training and Promotions are also used as a motivation tools. Job Appreciation, Rotation and Redesign are used as a motivation tools for a few employees.

3. Do you think training is an important tool to motivate employees?

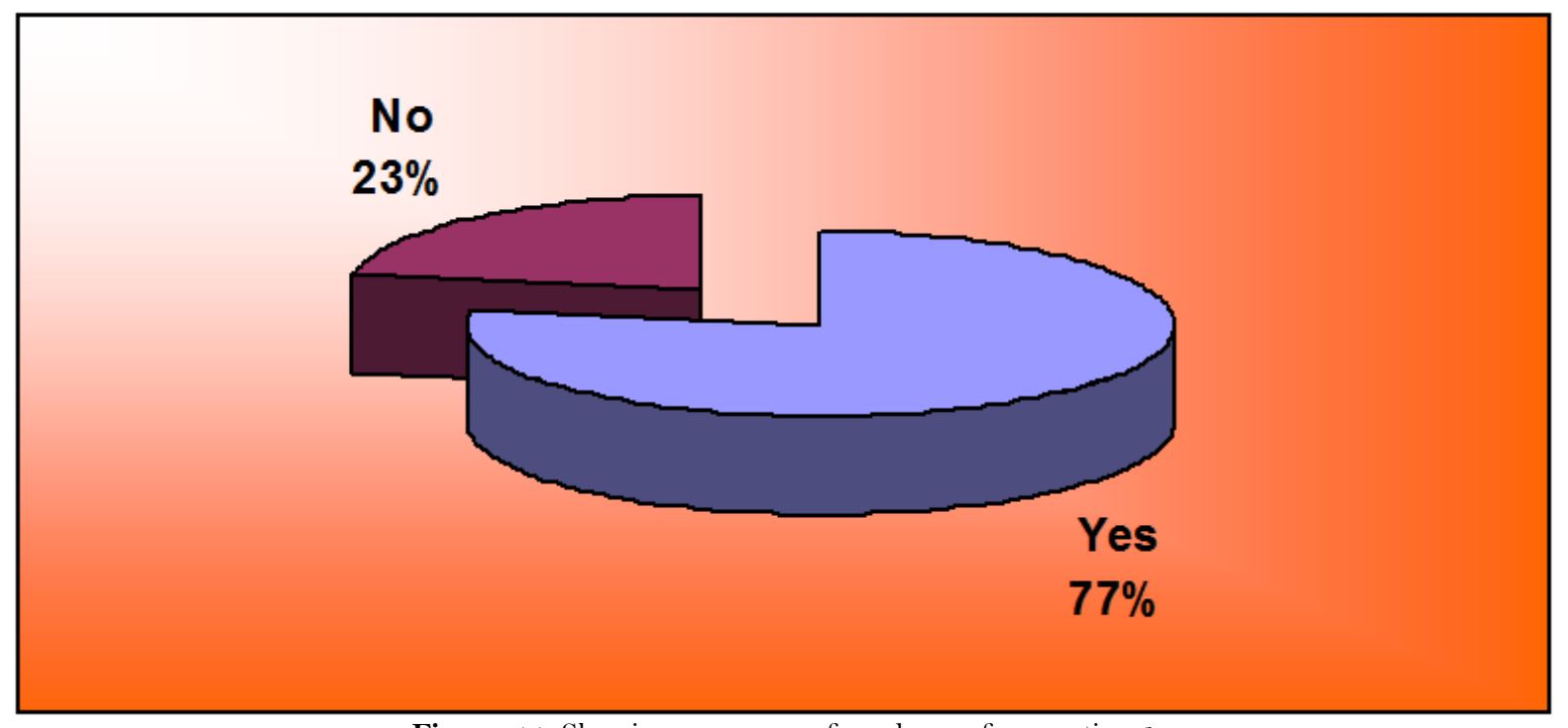

Source: Self made from the responses of the questionnaire

Interpretation: Above graph shows that $77 \%$ of the respondents agreed and $23 \%$ of the respondents did not agree with the statement that training is an important tool to motivate the employees in the organization.

4. How many days of training are imparted to a person in a calendar year?

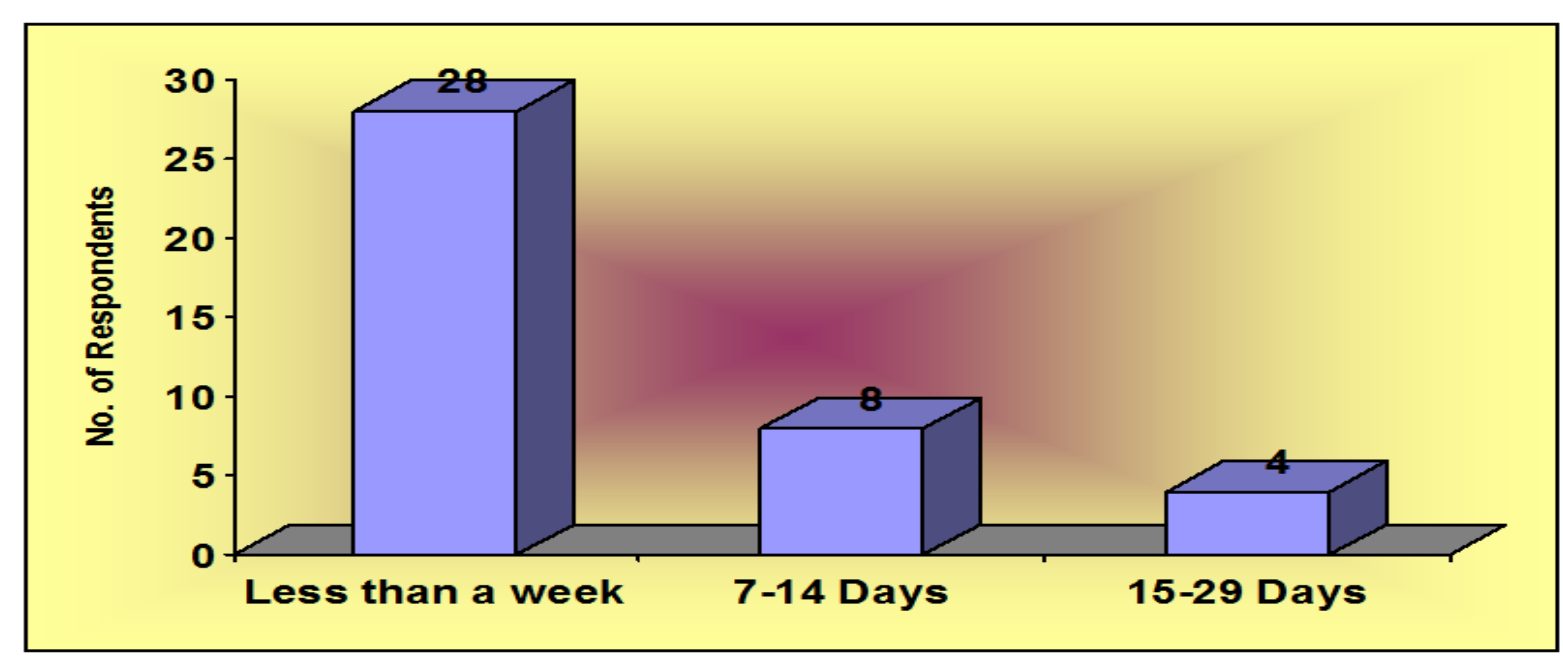

Figure-12. Showing re
Source: Self made from the responses of the questionnaire 
Interpretation: Above graph shows that at least $70 \%$ of the respondents conform to the fact that in one financial year they are imparted training for less than a week.

5. What all Training Programmes have you undergone in the last calendar year? (List any two)

The following training has been imparted to hotel employees in the last calendar year: Front Office, Induction of various departments, Front Office Cashing, Bomb Threat Training, Fire Fighting \& safety, Personal Hygiene, Stress management, Guest Satisfaction Programme, and Grooming.

6. Are the training programmes in your organization evaluated for improvement in skills and overall performance?

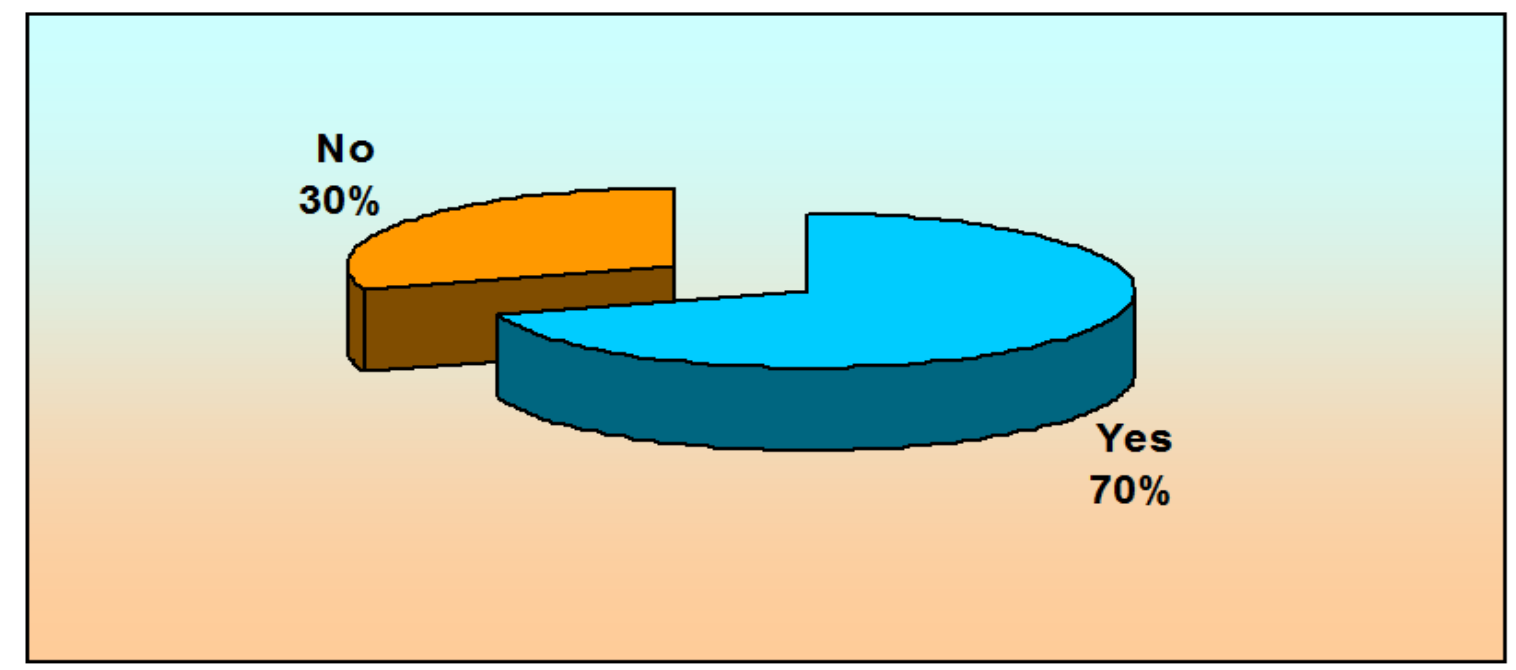

Figure-13. Showing responses of employees for question 4

Source: Self made from the responses of the questionnaire

Interpretation: About $70 \%$ of the respondents agree and $30 \%$ of the respondents do not agree to the statement that training program in their organization is evaluated for improvement in skills and overall performance.

7. How do you rate the training you have undergone on a scale of 1-4? (1- least, 4- most)

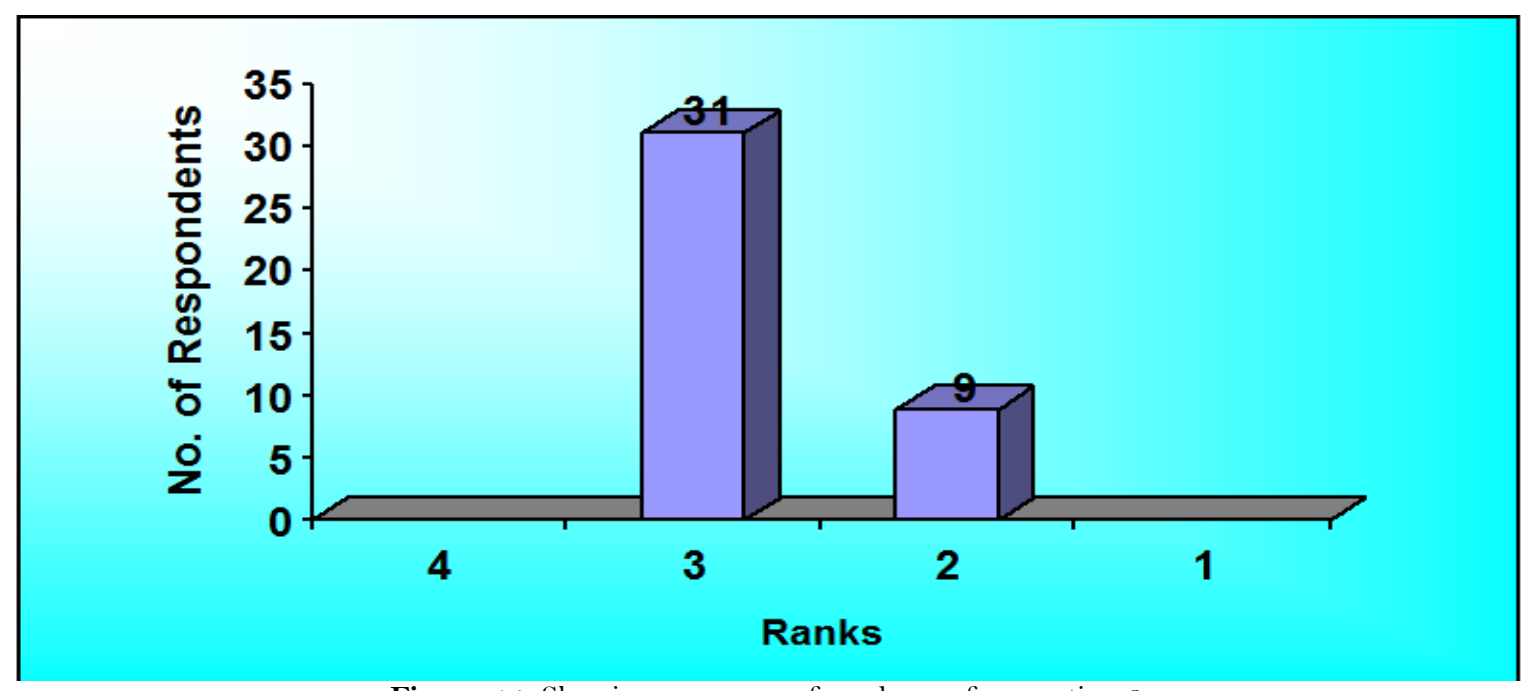

Source: Self made from the responses of the questionnaire

Interpretation: The above graph shows that $23 \%$ of the respondents have rated the training undertaken by them on a scale of 2 while $77 \%$ of the respondents have rated it on a scale of 3 .

\section{Findings}

The objectives were to find the factors which motivate the employees, evaluate the training methods and to find whether training is still an effective tool to motivate employees in the hospitality industry or not. Following are the findings of the study:

- Hotels from time to time impart training to managers and employees and these trainings improve the quality and quantity of work done by them. The training also creates more favorable attitudes, loyalty and cooperation from the employees towards the organization. These trainings enable the workers in their self-improvement and headway and furthermore to help associations to react to dynamic economic situations and changing shopper requests.

- The training programmes are different for different levels of employees like stress management training are specifically designed for Managers, which are in line with their job profile. Some training programmes are specifically designed for the employee's day-to-day needs and as per their departments. There is some training like Hygiene, Fire and safety, which are common to all the employees of the hotel.

- The various training programs for hotel staff are problem solving, role-playing, simulation and complaint handling.

- All the managers disagree to the statement that Motivation comes from within an individual. No amount of practices can influence motivation levels of employees. They agree to the fact that motivation and productivity of employees are interrelated. The most important factor that motivates employees as per the managers is salary and wages. The Managers think that training is an important tool to enhance the performance of 
employees. Though the purpose of training program to prepare the employees for future assignments in the same position but still has a motivational element.

- All the training programs conducted by Hotel are evaluated for effectiveness. The hotel's Managers have ranked their training programme as 4, which mean they are of the view that Hotel Training programmes are in line with the interest of organization and individual.

- About $85 \%$ of the employees agree that motivation leads to improved productivity.

- The work environment in the hospitality sector is a challenging one. It provides opportunity for growth and advancement with a working environment that can be considered the best in the industry. But with the rewards and benefits come long working hours, demanding seniors and stress.

- Managers do not actually motivate their employees because motivation is internal to each individual. Motivation cannot be viewed directly; as with the wind, only the results are observable. Management's job is to provide an organizational culture that encourages positive employee behaviors. Hence management in today's environment however, cannot rely on the financial rewards, improved working conditions or empowerment to stimulate workers to perform effectively. Motivation is a much more complicated process. Employers/managers need to understand those forces, which influence workers' behaviors. A manager's major motivational task is to develop and maintain environment, in which workers will want to be productive, contributing members of the organization.

- Today's human resource management professionals must recognize that in order to achieve a corporate culture that fosters improved productivity, employee's whether on a managerial position or on operational level personal needs must be reasonably well satisfied.

- So to achieve organizational goals the management must try to get the maximum quality output from their employees. To give the quality and quantity output the employees must be ready to give in their best to whatever they do and this is possible when their basic needs are satisfied. A satisfied worker is the one who can give his best performance because than he is able to concentrate on his job and is not bothered about his basic needs. Once these need level is achieved an individual starts looking for the next level of needs. These necessities if cultivated by the businesses will teach a feeling of faithfulness and incite him to give his best to every one of his assignments. Thus leading to a high order of performance and thus the highest order of productivity.

- Training is also an important part of HR activities when employees are transferred to other departments or promoted to higher positions in the organizations. Training is also an important part of the appraisal procedures and at times used by the Hotel management to motivate employees.

\section{Conclusions}

It is difficult enough to try and define what makes oneself 'tick', without trying to understand other people's motivations. The fact that there are so many theories of motivations is an indication of the complexities of the issue. Perhaps the most important point for the potential manager is to consider is that there is a very wide range of ways in which someone may be motivated. On the off chance that HR must be produced, the association ought to make conditions in which individuals obtain new learning and abilities and create sound examples of conduct and styles. One of the fundamental instruments of accomplishing this condition is preparing.

Preparing is basic since innovation is growing consistently and at a quick rate. Frameworks and practices get obsolete soon because of new revelations in innovation, including specialized, administrative and behavioral angles. Associations, which don't create systems to make up for lost time with and utilize the developing innovation, soon end up obsolete. Preparing and improvement are essential exercises in all associations, expansive and little. Each association, paying little mind to estimate, needs all around prepared representatives in its workforce who are set up to play out their employments.

For the hotel industry in particular training is a useful tool for an effective development of the available human resource. The job in a hotel involves lot of work pressures and the employees need to be able to cope with this. Though the purpose of training in Hotel is to prepare the employees for future assignments but still training empowers him with knowledge and skill, which in turn affects his motivation level.

The study has proved through the survey of Managers and employees of Oberoi Hotel in New Delhi that training still leads to motivation of employees. Thus Training although traditional, still retains its position as an important motivational tool.

\section{Recommendations}

Training and Motivation in hospitality industry is a vast topic of discussion. The organizations use different tools to motivate employees. Training is one of the effective tools used by Hotels to empower and motivate employees. To discuss the relevance of training and motivation in itself is very vast topic and cannot be done in a single study. It will require a lot of further research in different Hotel segments and employee segments to get an overall view of Training and Motivation of Hotel employees. It is recommended that further research be done with more sample size and more hotels in India to gauge the importance of training as a motivation tool.

\section{References}

Aarabi, M.S., I.D. Subramaniam and A.B.A.A.B. Akeel, 2013. Relationship between motivational factors and job performance of employees in Malaysian service industry. Asian Social Science, 9(9): 301-310. View at Google Scholar | View at Publisher

Alam, S.M.T., 2015. Factors affecting job satisfaction, motivation and turnover rate of medical promotion officer (MPO) in pharmaceutical industry: A study based in Khulna city. Asian Business Review, 1(2): 126-131. View at Google Scholar | View at Publisher

Chauhan, V., 2015. Relevance of non-monetary incentives in an organization. Retrieved from https://ssrn.com/abstract=2623828 or http://dx.doi.org/10.2139/ssrn.2623828.

Downes, P.E., A.L. Kristof-Brown, T.A. Judge and T.C. Darnold, 2017. Motivational mechanisms of self-concordance theory: Goal-specific efficacy and person-organization fit. Journal of Business and Psychology, 32(2): 197-215. View at Google Scholar $\mid$ View at Publisher 
Hussein, I.A., 2017. Effect of employee motivation on organizational performance of Mogadishu al port in Somalia. Strategic Journal of Business \& Change Management, 4(2): 89-97. View at Google Scholar

Kilam, I.K. and N. Kumari, 2012. Career planning and HRD climate-A major HR challenge for public sector banks in India. Asian Journal of Multidimensional Research, 1(7): 60-82. View at Google Scholar

Kumari, N., 2011. A live study of employee satisfaction and growth analysis: Tata steel. European Journal of Business and Management, 3(10): 53-62. View at Google Scholar

Kumari, N., 2014. Using performance appraisal as an effective tool for motivating the employees performance: A live study. Business Perspectives and Research, 2(2): 37-46. View at Google Scholar | View at Publisher

Kumari, N., 2015. The effectiveness of the training program at HCL. The East Asian Journal of Business Management, 5(3): 23-28. View at Google Scholar

Kumari, N., 2015. Emotional intelligence as a predictor of conflict resolution style. Research Journal of Business Management, 9(2): 350-363. View at Google Scholar | View at Publisher

Kumari, N., 2016. Study of employee satisfaction in hotel industry. Management and Administrative Sciences Review, 5(2): 118 - 127. View at Google Scholar

Nandhini, P., 2017. A study on impact of motivational factors on job satisfaction in construction company at Chennai. International Journal of Management Research and Reviews, 7(3): 220-224. View at Google Scholar

Pramanik, S. and I. Chatterjee, 2015. Intrinsic motivation, emotional intelligence, and perceived organizational citizenship behavior among employees in service organizations. Prabandhan: Indian Journal of Management, 8(12): 33-43. View at Google Scholar $\mid$ View at Publisher

Rao, M.S. and M.S. Rao, 2017. Innovative tools and techniques to ensure effective employee engagement. Industrial and Commercial Training, 49(3): 127-131. View at Google Scholar | View at Publisher

Serrat, O., 2017. Building a learning organization. In knowledge solutions. Singapore: Springer. pp: 57-67. 